PREPARED FOR THE U.S. DEPARTMENT OF ENERGY, UNDER CONTRACT DE-AC02-76CH03073

PPPL-3832

PPPL-3832

UC-70

Numerical Study of Instabilities Driven

by Energetic Neutral Beam Ions in NSTX

by

E.V. Belova, N.N. Gorelenkov,

C.Z. Cheng, and E.D. Frerickson

July 2003

NM|

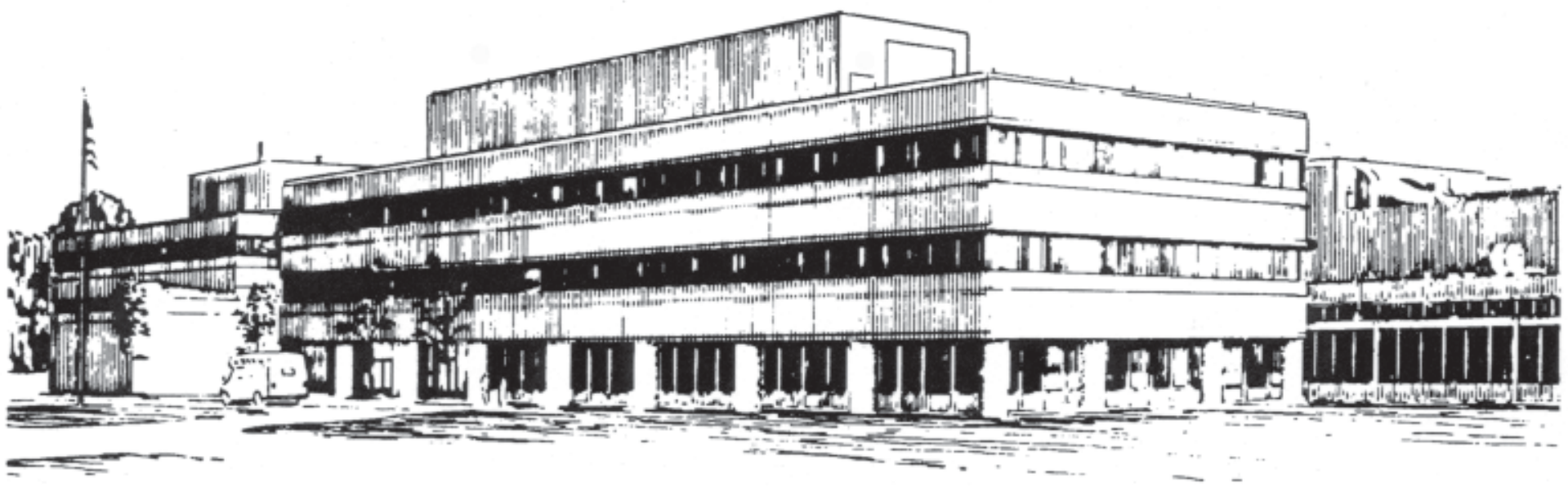

PRINCETON PLASMA PHYSICS LABORATORY PRINCETON UNIVERSITY, PRINCETON, NEW JERSEY 


\section{PPPL Reports Disclaimer}

This report was prepared as an account of work sponsored by an agency of the United States Government. Neither the United States Government nor any agency thereof, nor any of their employees, makes any warranty, express or implied, or assumes any legal liability or responsibility for the accuracy, completeness, or usefulness of any information, apparatus, product, or process disclosed, or represents that its use would not infringe privately owned rights. Reference herein to any specific commercial product, process, or service by trade name, trademark, manufacturer, or otherwise, does not necessarily constitute or imply its endorsement, recommendation, or favoring by the United States Government or any agency thereof. The views and opinions of authors expressed herein do not necessarily state or reflect those of the United States Government or any agency thereof.

\section{Availability}

This report is posted on the U.S. Department of Energy's Princeton Plasma Physics Laboratory Publications and Reports web site in Fiscal Year 2003. The home page for PPPL Reports and Publications is: http://www.pppl.gov/pub_report/

DOE and DOE Contractors can obtain copies of this report from:

U.S. Department of Energy

Office of Scientific and Technical Information

DOE Technical Information Services (DTIS)

P.O. Box 62

Oak Ridge, TN 37831

Telephone: (865) 576-8401

Fax: (865) 576-5728

Email: reports@adonis.osti.gov

This report is available to the general public from:

National Technical Information Service

U.S. Department of Commerce

5285 Port Royal Road

Springfield, VA 22161

Telephone: $1-800-553-6847$ or

(703) $605-6000$

Fax: (703) 321-8547

Internet: http://www.ntis.gov/ordering.htm 


\title{
Numerical Study of Instabilities Driven by Energetic Neutral Beam Ions in NSTX
}

\author{
E. V. Belova, N. N. Gorelenkov, C. Z. Cheng, and E. D. Fredrickson \\ Princeton Plasma Physics Laboratory, P. O. Box 451, Princeton, NJ 08543, USA
}

Recent experimental observations from NSTX suggest that many modes in a subcyclotron frequency range are excited during neutral beam injection (NBI) [1]. These modes have been identified as Compressional Alfvén Eigenmodes (CAEs) and Global Alfvén Eigenmodes (GAEs), which are driven unstable through the Doppler shifted cyclotron resonance with the beam ions [2]. The injection velocities of the NBI ions in NSTX are large compared to Alfvén velocity, $V_{0}>3 V_{A}$, and a strong anisotropy in the fast-ion pitch-angle distribution provides the energy source for the instabilities. Recent interest to the excitation of Alfvén Eigenmodes in the frequency range $\omega \lesssim \omega_{c i}$, where $\omega_{c i}$ is the ion cyclotron frequency, is related to the possibility that these modes can provide a mechanism for direct energy transfer from super-Alfvénic beam ions to thermal ions [3]. Numerical simulations are required in order to find a self-consistent mode structure, and to include the effects of finite Larmor radius (FLR), the nonlinear effects, and the thermal plasma kinetic effects.

We have performed 3D hybrid simulations using HYM code [4] to study the excitation of Alfvén Eigenmodes by energetic ions in NSTX. The HYM code is a nonlinear, global stability code in toroidal geometry, which includes fully kinetic ion description. In the numerical model, beam ions are treated using full-orbit, delta-f particle simulations, while the one-fluid resistive MHD model is used to represent the background plasma. The two plasma components are coupled using a current coupling scheme. In this scheme, the momentum equation for the thermal plasma is

$$
\rho_{p} \frac{d \mathbf{V}_{p}}{d t}=-\nabla p_{p}+\left(\mathbf{J}-\mathbf{J}_{b}\right) \times \mathbf{B} / c-q n_{b}(\mathbf{E}-\eta \mathbf{J})+\nu \Delta \mathbf{V}_{p}
$$

where $\rho_{p}, \mathbf{V}_{p}$, and $p_{p}$ are the thermal plasma density, velocity and pressure; $n_{b}$ and $\mathbf{J}_{b}$ are the beam ion density and the beam ion induced current, $\nu$ is a viscosity coefficient, and $\mathbf{J}$ is the total plasma current. It is assumed that the fast ion pressure can be comparable to that of the thermal plasma, but the beam ions have a low density $n_{b} \ll n_{p}$. In this case, the MHD Ohm's law applies: $\mathbf{E}=-\mathbf{V}_{p} \times \mathbf{B} / c+\eta \mathbf{J}$.

The delta-f method is used to reduce numerical noise in the simulations. In this method, the equilibrium distribution function of NBI ions needs to be known analytically, 
and the equation for the perturbed distribution function $\delta F=F-F_{0}$ is integrated along the particle trajectories. Equilibrium distribution function is taken to be in the form [4]: $F_{0}=F_{1}(v) F_{2}(\lambda) F_{3}\left(p_{\phi}\right)$, where $v=\sqrt{2 \varepsilon}$ is the particle velocity, $\lambda \equiv \mu B_{0} / \varepsilon$ is the pitchangle variable, $p_{\phi}=-\psi+R v_{\phi}$, and functions $F_{1,2,3}$ are defined by

$$
\begin{aligned}
F_{1}(v) & =\frac{1}{v^{3}+v_{*}^{3}}, \quad \text { for } v<v_{0}, \\
F_{2}(\lambda) & =C \exp \left(-\left(\lambda-\lambda_{0}\right)^{2} / \Delta \lambda^{2}\right), \\
F_{3}\left(p_{\phi}\right) & =\frac{\left(p_{\phi}-p_{\min }\right)^{\alpha}}{\left(p_{\max }-p_{\min }\right)^{\alpha}}, \text { for } p_{\phi}>p_{\min },
\end{aligned}
$$

where $F_{0}=0$ for $v>v_{0}$ or $p_{\phi}<p_{\min } ; v_{0} \approx 3.5 V_{A}$ is the injection velocity, and we assumed $v_{*}=v_{0} / 2$. The pitch-angle distribution is typically relatively narrow with $\Delta \lambda=0.3$, and $\lambda_{0}=0.5-0.8$. The function $F_{3}\left(p_{\phi}\right)$ is used to match the TRANSP profiles of the beam ion density, where $\alpha$ is a numerical parameter, and the condition $p_{\phi}>p_{\min }$ describes a promptloss boundary. A generalized form of the Grad-Shafranov equation has been derived [4], which includes, non-perturbatively, the effects of the beam ion toroidal and poloidal currents, and it is used to calculate self-consistent equilibria, which serve as an initial condition for the 3D simulations.

Simulation results for typical NSTX parameters show that for large injection velocities of beam ions, $V_{0}>3 V_{A}$, and strong anisotropy in the pitch-angle distribution, many Alfvén modes can be excited (such as shown in Figs. 1 and 2). The instabilities are driven by the resonant beam ions, which satisfy the condition:

$$
\omega-k_{\|} v_{\|}-\omega_{c i}=0,
$$

in which the perpendicular drift frequency is not shown, because it is typically small compared to other terms in Eq. (5). It is found that the most unstable modes for low toroidal mode numbers, $2<n<7$, are GAE modes [5]. These modes are found to be localized near the magnetic axis, and have large $k_{\|}$(with $n m<0$, where $m$ is the poloidal mode number), so that $\omega \sim\left|k_{\|} v_{\|}\right| \sim 0.5 \omega_{c i}$. The linear mode structure of GAE mode with $n=4$ and $m=-2$ is shown in Fig. 1 and Fig. 3. The poloidal velocity has a vortex-like structure, which is characteristic for a shear Alfvén wave; however in NSTX, these modes have a significant compressional component, $\delta B_{\|} \approx 1 / 3 \delta B_{\perp}$, due to strong coupling to the compressional Alfvén wave. For each $n$, several GAE modes with different (dominant) $m$ are unstable (Fig. 4). Linearized simulations for different $n$ show that for the most unstable modes, a condition $n+m \approx 6$ is satisfied (i.e. approximately same $k_{\|}$). 

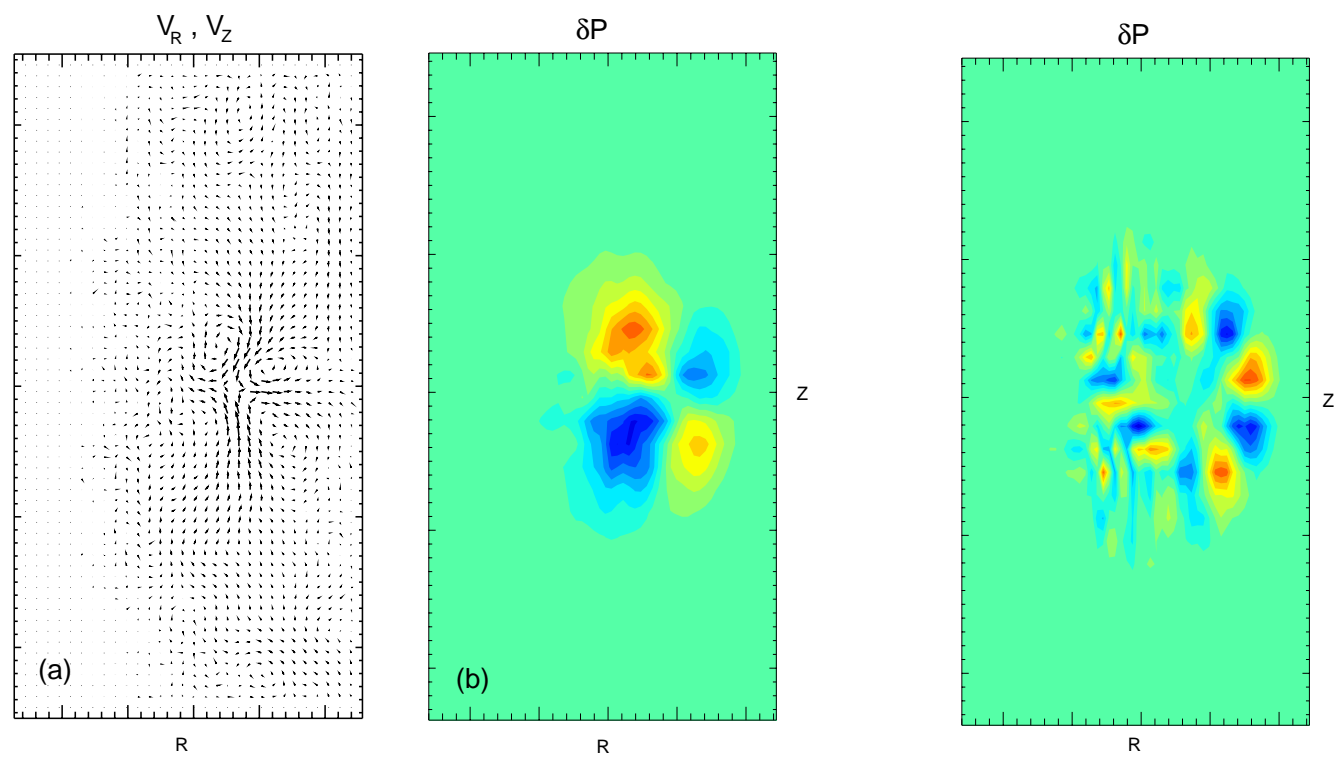

Figure 1: Poloidal structure of $n=4, m=-2 G A E$ mode: (a) vector plot of poloidal velocity, and (b) contour plot of fluid pressure perturbation.

Figure 2: Poloidal structure of CAE mode: contour plot of fluid pressure perturbation, $n=8$.

General properties of GAE modes have been studied previously both in cylindrical and toroidal geometries [5]. A GAE mode is a global (regular) mode with frequency just below the minimum of the Alfvén continuum $\omega<\min \left(\omega_{A}\right)$, and owes its existence to the coupling between the shear and compressional waves. For a very flat $q$ profile, typical for NSTX, the minimum of $\omega_{A}^{2}(r)$ occurs at the magnetic axis $(r=0)$, resulting in the mode localization near $r=0$. Due to their localization, the main features of GAE modes observed in NSTX simulations are very similar to cylindrical GAE modes. Radial extent of unstable GAE modes is found to be smaller for larger $m$.

Previous studies of energetic particle excitation of GAE modes were performed for fast ion velocities $V_{0} \sim V_{A}$, and considered a resonant excitation for: $\omega \approx k_{\|} v_{\|}$[5]. In this case, the GAE growth rates were found to be small $\gamma \sim 0.001 \omega$, and therefore, these modes were found to be strongly damped by the resonant electrons (in cylinder) and due to sideband (mostly $m+1$ ) coupling to continuum (in toroidal geometry) [5]. (In contrast, low-frequency TAE modes were found to be more dangerous, with larger growth rates, due to $\gamma \sim 1 / k_{\|}^{2}$.)

For NSTX, the injection velocities are large, $V_{0}>3 V_{A}$, and the cyclotron resonance condition Eq. (5) can be satisfied. This resonant instability has different dependence on $k_{\|}$, and larger $k_{\|}$modes can be strongly unstable, including the GAE modes, which are intrinsically high- $k_{\|}$modes. Thus, in HYM simulations for $n_{b} / n_{p}=0.03$ and the beam 


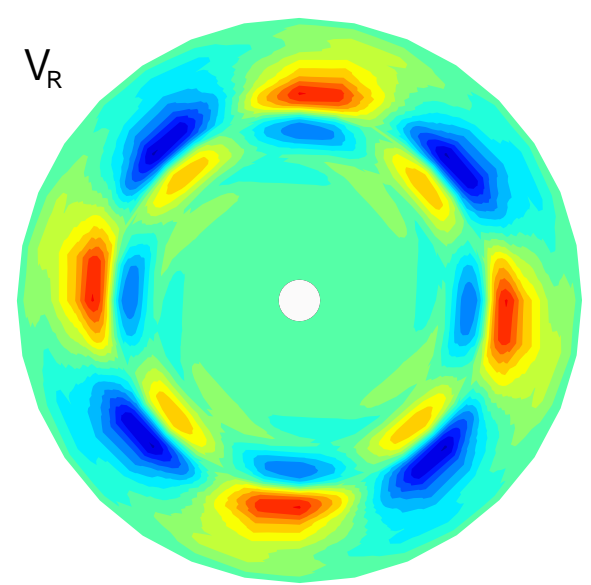

Figure 3: Contour plot of radial component of fluid velocity at equatorial plane for $n=4$ GAE mode.

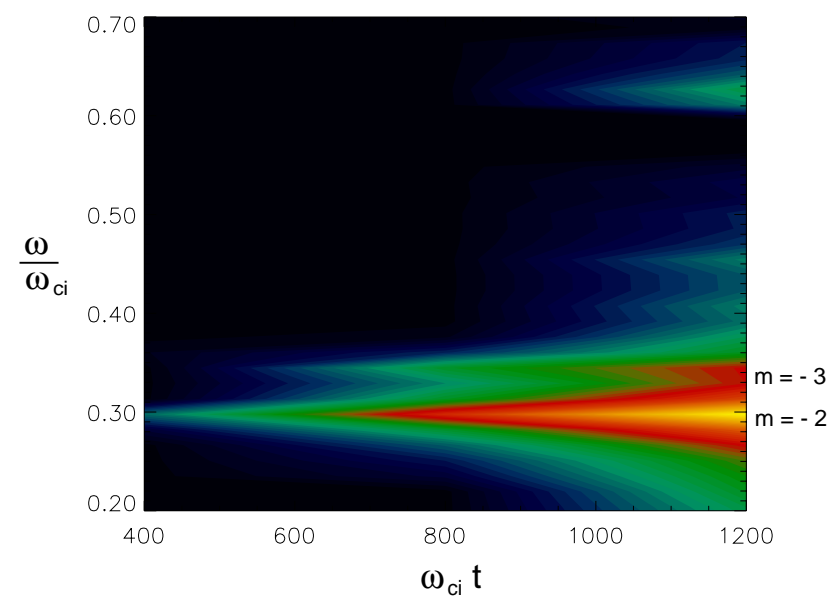

Figure 4: Time evolution of spectrum of unstable modes for $n=4$. Lower frequency modes are GAE modes with $m=-2$ and -3 .

energy $E=80 \mathrm{keV}$, growth rates of unstable GAE modes are found to be of the order $\gamma \approx$ $0.002-0.01 \omega_{c i}$ with frequencies $\omega \approx 0.3-0.5 \omega_{c i}$. Electron Landau damping for GAE modes is found to be negligible [2], and it is not included in our model. The continuum damping is included due to viscous terms in Eq. (1), however no strong resonance coupling to continuum modes is seen in linear simulations, perhaps due to a low mode amplitude at the resonance location. Preliminary nonlinear simulations show saturation of the GAE mode growth at low amplitudes with $\delta B \sim 10^{-4}-10^{-3} B_{0}$.

Instabilities of compressional CAE modes are not identified in simulations with low $n$, perhaps because of the growth of more unstable GAE modes. However, for larger $n$, modes with a large compressional component $\delta B_{\|}>\delta B_{\perp}$ (CAE) and growth rates $\gamma \sim 0.001 \omega_{c i}$ are excited (Fig. 2). Unlike GAE, compressional modes are found to be localized on the low field side, and have small parallel wave numbers $(\mathrm{nm}>0)$. Future work will include investigation of the conditions for preferable excitation of CAE and GAE modes, and studies of their nonlinear evolution.

[1] E. D. Fredrickson, et al., Phys. Rev. Lett. 87, 145001 (2001).

[2] N. N. Gorelenkov, et al., Nucl. Fusion 42, 977 (2002).

[3] D. A. Gates, et al., Phys. Rev. Lett. 87, 205003 (2001).

[4] E.V. Belova et al., Phys. Plasmas 10, in press (2003); 7, 4996 (2000).

[5] K. Appert et al., Plasma Phys. 24, 1147 (1982); J. W. Van Dam et al., Fusion Tech. 18, 461 (1990).

Research supported by the U.S. DOE under contract No. DE-AC02-76CH03073. 


\section{External Distribution}

Plasma Research Laboratory, Australian National University, Australia

Professor I.R. Jones, Flinders University, Australia

Professor João Canalle, Instituto de Fisica DEQ/IF - UERJ, Brazil

Mr. Gerson O. Ludwig, Instituto Nacional de Pesquisas, Brazil

Dr. P.H. Sakanaka, Instituto Fisica, Brazil

The Librarian, Culham Laboratory, England

Mrs. S.A. Hutchinson, JET Library, England

Professor M.N. Bussac, Ecole Polytechnique, France

Librarian, Max-Planck-Institut für Plasmaphysik, Germany

Jolan Moldvai, Reports Library, Hungarian Academy of Sciences, Central Research Institute for Physics, Hungary

Dr. P. Kaw, Institute for Plasma Research, India

Ms. P.J. Pathak, Librarian, Institute for Plasma Research, India

Ms. Clelia De Palo, Associazione EURATOM-ENEA, Italy

Dr. G. Grosso, Instituto di Fisica del Plasma, Italy

Librarian, Naka Fusion Research Establishment, JAERI, Japan

Library, Laboratory for Complex Energy Processes, Institute for Advanced Study, Kyoto University, Japan

Research Information Center, National Institute for Fusion Science, Japan

Dr. O. Mitarai, Kyushu Tokai University, Japan

Dr. Jiangang Li, Institute of Plasma Physics, Chinese Academy of Sciences, People's Republic of China

Professor Yuping Huo, School of Physical Science and Technology, People's Republic of China

Library, Academia Sinica, Institute of Plasma Physics, People's Republic of China

Librarian, Institute of Physics, Chinese Academy of Sciences, People's Republic of China

Dr. S. Mirnov, TRINITI, Troitsk, Russian Federation, Russia

Dr. V.S. Strelkov, Kurchatov Institute, Russian Federation, Russia

Professor Peter Lukac, Katedra Fyziky Plazmy MFF UK, Mlynska dolina F-2, Komenskeho Univerzita, SK-842 15 Bratislava, Slovakia

Dr. G.S. Lee, Korea Basic Science Institute, South Korea

Institute for Plasma Research, University of Maryland, USA

Librarian, Fusion Energy Division, Oak Ridge National Laboratory, USA

Librarian, Institute of Fusion Studies, University of Texas, USA

Librarian, Magnetic Fusion Program, Lawrence Livermore National Laboratory, USA

Library, General Atomics, USA

Plasma Physics Group, Fusion Energy Research Program, University of California at San Diego, USA

Plasma Physics Library, Columbia University, USA

Alkesh Punjabi, Center for Fusion Research and Training, Hampton University, USA

Dr. W.M. Stacey, Fusion Research Center, Georgia Institute of Technology, USA

Dr. John Willis, U.S. Department of Energy, Office of Fusion Energy Sciences, USA

Mr. Paul H. Wright, Indianapolis, Indiana, USA 
The Princeton Plasma Physics Laboratory is operated by Princeton University under contract with the U.S. Department of Energy.

\author{
Information Services \\ Princeton Plasma Physics Laboratory \\ P.O. Box 451 \\ Princeton, NJ 08543
}

Phone: 609-243-2750

Fax: 609-243-2751

e-mail: pppl_info@pppl.gov

Internet Address: http://www.pppl.gov 